\title{
Utilization of and Demand for Reproductive Health Services among 20-39-Year-Old Women in Rural China: A Cross-Sectional Study
}

\section{Jing Yue}

Central South University Xiangya School of Nursing

Yang Luo ( $\square$ ly603202@csu.edu.cn )

Central South University https://orcid.org/0000-0002-0706-6323

\section{Chen Xu}

Central South University Xiangya School of Nursing

Si Qin

Central South University Xiangya School of Nursing

\section{Yanting Meng}

Central South University Xiangya School of Nursing

\section{Ling Fan}

Central South University Xiangya School of Nursing

Min Nie

Central South University Xiangya School of Nursing

\section{Research}

Keywords: Reproductive health, Service, Utilization, Demand, China

Posted Date: November 6th, 2020

DOl: https://doi.org/10.21203/rs.3.rs-102657/v1

License: (c) (i) This work is licensed under a Creative Commons Attribution 4.0 International License. Read Full License 


\section{Abstract}

Background: The enjoyment of reproductive health $(\mathrm{RH})$ services is a universal right for all human beings. The rural population serves an important role in economic and social development. However, little is known about the rural population's RH services, especially in low and middle-income countries. Our study aimed to determine the utilization of and demand for $\mathrm{RH}$ services in rural China, which is the most populous country in the world with $40.42 \%$ rural populations.

Methods: A cross-sectional study was conducted in four villages of four cities in Hunan province among 978 women who were 20-39 years old. A researcher-made structured questionnaire was used to collect data. The data were entered into EpiData version 3.0 and analyzed by SPSS version 18.0. Statistical significance was defined as a two-sided $P$ value of less than 0.05 .

Results: Among the 980 women who were recruited in this study, 978 participants completed the questionnaire as requested (response rate: 99.8\%). Age, monthly household income, employment, spousal education level, and artificial abortion history were associated with the utilization of RH services $(P \otimes 0.05)$. The top three $\mathrm{RH}$ services participants utilized were free antenatal examinations $(90.2 \%)$, free postpartum visits $(73.0 \%)$, and free folic acid supplements $(71.6 \%)$. The top three RH services they most wanted to obtain were prevention of cervical/breast cancer (58.9\%), child health care $(48.2 \%)$, and reproductive tract infection/sexually transmitted disease treatment (41.1\%). The most commonly used method for participants to obtain information related to $\mathrm{RH}$ services was the internet.

Conclusions: It is necessary to further improve the accessibility and availability of RH services to ameliorate the utilization of these services in rural areas. The internet was the most effective method for improving the use of RH services. Educational interventions and policy support help promote $\mathrm{RH}$ services in rural China.

\section{Plain English Summary}

Reproductive Health $(\mathrm{RH})$ services has been recognized worldwide as a cost-effective, first-line preventive strategy to promote $\mathrm{RH}$. However, little is known about the rural population's RH services, especially in low and middle-income countries. After the implementation of China's Universal Two-Child Policy, women between 20 and 39 years old will face more $\mathrm{RH}$ problems related to childbirth, especially in backward rural areas. This unknown merits a specialized study to promote equal access to $\mathrm{RH}$ services.

Our study investigated the utilization of and demand for RH services in rural China, which is the most populous country in the world with $40.42 \%$ rural populations. Among the 978 participants, Age, monthly household income, employment, spousal education level, and artificial abortion history were associated with the utilization of $\mathrm{RH}$ services $(P<0.05)$. The top three $\mathrm{RH}$ services participants utilized were free antenatal examinations, free postpartum visits, and free folic acid supplements. The top three $\mathrm{RH}$ services they most wanted to obtain were prevention of cervical/breast cancer, child health care, and 
reproductive tract infection/sexually transmitted disease treatment. The most commonly used method for participants to obtain information related to $\mathrm{RH}$ services was the internet.

In conclusion; it is necessary to further improve the accessibility and availability of RH services to ameliorate the utilization of services in rural areas. This finding suggests that future efforts should target high-risk populations of women by providing them with RH-related information and cultivating positive attitudes toward $\mathrm{RH}$ services.

\section{Background}

Reproductive health $(\mathrm{RH})$ refers to a state of complete physical, mental, and social well-being (and not merely the absence of disease or infirmity) in all matters relating to the reproductive system and its functions and processes [1]. RH is closely related to human reproduction and social development [2]. RH services refer to the medical and health services provided for the realization of reproductive health, including sex education, sexual and reproductive health consultation, contraceptives, and medical and health services [3]. The United Nations (UN) Sustainable Development Goals (SDG) propose to ensure universal access to sexual and reproductive health care services by 2030 [4]. Therefore, the enjoyment of $\mathrm{RH}$ services is a universal right that is essential to all human beings [5].

$\mathrm{RH}$ services has been recognized worldwide as a cost-effective, first-line preventive strategy to promote reproductive health. For example, global coverage for a full course of human papillomavirus (HPV) vaccines was only $12 \%$ in 2018 and supplies have yet to reach the poorest countries, where the risk of cervical cancer is the greatest [6]. RH screening remains the most effective preventative measure. To take another example of the usefulness of RH services, birth defects and their reduction have long been a challenge, despite the existence of effective interventions. In China, due to the huge population base, there are about 900,000 new birth defects every year, equivalent to one birth defect every 30 seconds [7]. After implementing policies to improve the utilization of $\mathrm{RH}$ services, the Chinese child mortality rate due to birth defects decreased from 3.5\%o to 1.6\%o between 2007 and 2017 [8].

Rural economic development is backward and the medical and health conditions are poor. There are 34 billion rural people in the world, accounting for $44 \%$ of the total population [9]. As the most populous country in the world, the rural population accounts for $40.42 \%$ of the total population in China. Hunan Province, as a major province in central China, has a rural population of 30.34 million. The birth rate there was the highest of the three regions (western, central, and eastern China) at $12.19 \%$ o compared with $10.35 \%$ in eastern China and $11.24 \%$ in western China in 2018 [10]. A high birth rate means more demand for RH services. Especially after the implementation of the Universal Two-Child Policy, every couple was encouraged to have two children [11]. Women between 20 and 39 years old will face more RH problems related to childbirth.

Although the government has proposed some plans to promote equal access to $\mathrm{RH}$ services, the utilization is unknown and the demand is undefined. This uncertainty merits a specialized study to systematically evaluate, so as to promote equal access to RH services. Our study was the first to 
investigate the utilization of and demand for $\mathrm{RH}$ services among 20-39-year-old women in rural areas in Hunan province, to identify RH services uptake and obstacles. Our intention was to make recommendations to promote the $\mathrm{RH}$ services utilization and reduce the incidence of $\mathrm{RH}$ problems.

\section{Methods}

\section{Study design and sampling}

This cross-sectional study was conducted in Hunan Province in cooperation with the Women's Federation of Hunan Provincial Government between May 30 and September 16, 2019. Hunan Province is in central China and has a population of 68.6 million. We selected one county each in the eastern (Loudi), western (Huaihua), southern (Chenzhou), and northern (Changde) regions of Hunan Province that we believed to be typical for each region in economics and demographics, then selected one city in each county. Next, multistage cluster sampling was used to recruit samples from these four selected cities. We randomly selected one township per city and one village from each township for a total of four villages.

\section{Sample size}

We determined the sample size using the equation of the random sampling method. According to a study for the floating population, the utilization rate of RH services in China was approximately $40 \%$ [15]. We chose an approximate value of $40 \%$ for the calculation of the sample size. The formula we used for the sample size calculation was $n=\mu^{2}{ }_{a} \times P \otimes 1-P \Downarrow / \delta^{2}$, where $a=0.05 \llbracket \mu_{a}=1.96, P$ means the overall rate of $R H$ services and $\delta=3.3 \%$. The sample size was calculated to be 847 . To reduce the sampling error and increase the study power, we arbitrarily made a rough estimation by multiplying the calculated sample size by $15 \%$, which led to a sample size of 974 . Finally, a total of 980 women who met the requirements were recruited in this study, and 978 (99.8\%) participants completed the questionnaire as requested.

\section{Participants}

An analysis of dynamic population monitoring data based on Hunan Province demonstrated that the fertility rate of women over 40 years was lower than $2.0 \%$ [13]. Thus, our study selected women aged 2039 years to investigate the utilization of and demand for $\mathrm{RH}$ services. The inclusion criteria were (1) females who were between 20 and 39 years old; (2) females who registered residences (hukou) in rural Hunan or lived in the investigated area for more than 6 months; and (3) females who provided oral informed consent. The exclusion criteria were cognitive impairment and the inability to complete the questionnaire independently.

\section{Measurements and data collection}


A Women's Reproductive Health Questionnaire (WRH-Q) was developed by the researchers after an extensive literature review and revised by a panel of 10 experts from Central South University, affiliated hospitals, and the Hunan Women's Federation. We recruited women through direct door to door visits. When the three door-to-door investigations were failure, the household was abandoned and supplemented in sequence from the alternate households.

The Women's Federation of Hunan Provincial Government trained the community health workers, who were local familiarity. The training contents included the content and purpose of the current study and the steps to collect questionnaires. Well-trained investigators conducted interviews with the eligible subjects and explained the purpose and procedures of the study. The anonymous questionnaires were either completed by the subjects themselves or with the help of the investigators in cases of subjects with limited literacy. Investigators checked the completeness and accuracy of each questionnaire on the spot.

\section{Socio-demographic and gestation data}

This part was developed to collect participant information for items related to the region, age, marital status, employment, monthly household income, education level, spouse education level, sexual behavior, artificial abortion history, pregnancy history, and delivery history.

\section{Utilization of $\mathrm{RH}$ services}

$\mathrm{RH}$ services for women of childbearing age in China mainly include consulting, premarital checkups, preconception care, antenatal examination, postpartum visits, and general gynecological investigation [14]. Depending on China's RH service content, this part of the questionnaire included: 1) Access to RH counseling. Participants would answer questions about whether she had gotten contraception counseling and pregnancy counseling. 2) Awareness of the free birth policy. Participants would answer the following questions: whether she had known about the basic public health service policy, free folic acid supplement policy, and free AIDS, syphilis, and hepatitis B testing. 3) Access to RH-related examinations or services. Participants would answer the following questions: whether she had received free folic acid supplements, free AIDS, syphilis and hepatitis B testing, free antenatal examinations, free preconception care, free postpartum visits, cervical cancer screening, and breast cancer screening.

\section{Demand for $\mathrm{RH}$ services}

The questionnaire also asked about the women's needs for RH services. 1) What type of RH services do you want to get? (Answers: prevention of cervical/breast cancer, child health care, reproductive tract infection/sexually transmitted disease treatment, psychological health care, pregnant/prenatal care, contraception climacteric hygiene, and others). 2) Which way do you most want to get $\mathrm{RH}$-related 
information? (Answers: medical staff, Internet, WeChat/Micro-blogs, radio and television, friends and family, books/newspapers/magazines, and brochures).

\section{Data analysis}

All data were independently double-entered and validated using EpiData (Version 3.0, The EpiData Association, Odense, Denmark). Data were analyzed with SPSS software (Version 18.0, Chicago: SPSS Inc.). Descriptive statistics were used to examine the socio-demographic factors and the statutes of the reproductive health services offering the samples. Logistic regression analyses were performed to examine the correlation factors of the utilization of RH services. Statistical significance was defined as a two-sided $P$ value of less than 0.05 . If more than $20 \%$ of the items had missing values, the questionnaire would be excluded as invalid.

\section{Ethical considerations}

The study was approved by the Ethical Committee of the Xiang Ya Nursing School, Central South University. Written consent was obtained from all respondents before the interviews.

\section{Results}

\section{Participants' socio-demographic and gestational characteristics}

Among the 980 women who were recruited in this study, 978 participants completed the questionnaire as requested (response rate: $99.8 \%$ ). Of the 978 women, $24.6 \%$ lived in Loudi, $23.8 \%$ lived in Chenzhou, $24.0 \%$ lived in Huaihua, and $27.5 \%$ lived in Changde. Most of the respondents were married women $(86.5 \%)$, and their average age was 30.2 years $(S D=4.9)$. Of the individuals, $64.5 \%$ were employed, $24.7 \%$ had received college education or above, and $21.3 \%$ of the partners had a college education or above. The average monthly household income (RMB) was between 5,000 and 10,000 for $32.9 \%$ and below 5,000 for $63.9 \%$. Of the 850 women who had a sexual life, 820 women had a history of pregnancy (96.5\%). Among the 820 women with a history of pregnancy, 257 had a history of artificial abortion (31.4\%), and 811 women had a history of delivery (98.9\%). The socio-demographic and gestational characteristics of the participants are summarized in Table 1. 
Table 1

Socio-demographic and gestational characteristics ( $N=978$ )

\begin{tabular}{|c|c|c|c|}
\hline Variables & Categories & Frequencies & Percentages \\
\hline \multirow[t]{4}{*}{ Region } & Loudi (east) & 241 & 24.6 \\
\hline & Chenzhou (south) & 233 & 23.8 \\
\hline & Huaihua (west) & 235 & 24.0 \\
\hline & Changde (north) & 269 & 27.5 \\
\hline \multirow[t]{3}{*}{ Age (years) } & $19-25$ & 186 & 19.0 \\
\hline & $26-32$ & 435 & 44.5 \\
\hline & $33-39$ & 357 & 36.5 \\
\hline \multirow[t]{2}{*}{ Marital status } & Unmarried & 132 & 13.5 \\
\hline & Married & 846 & 86.5 \\
\hline \multirow[t]{2}{*}{ Employment } & Unemployed & 347 & 35.5 \\
\hline & Employed & 631 & 64.5 \\
\hline \multirow[t]{3}{*}{ Monthly household income (CNY $\left.{ }^{*}\right)$} & $\nabla 5000$ & 625 & 63.9 \\
\hline & $5000-10000$ & 322 & 32.9 \\
\hline & $\otimes 10000$ & 31 & 3.2 \\
\hline \multirow[t]{4}{*}{ Education level } & Primary school or less & 53 & 5.4 \\
\hline & Junior school & 388 & 39.7 \\
\hline & Senior school & 295 & 30.2 \\
\hline & College or more & 242 & 24.7 \\
\hline \multirow[t]{4}{*}{ Spouse education level $(\mathrm{N}=846)$} & Primary school or less & 41 & 4.8 \\
\hline & Junior school & 332 & 39.3 \\
\hline & Senior school & 293 & 34.6 \\
\hline & College or more & 180 & 21.3 \\
\hline \multirow[t]{2}{*}{ Sexual behavior } & No & 128 & 13.1 \\
\hline & Yes & 850 & 86.9 \\
\hline \multirow[t]{2}{*}{ Pregnancy history ( $\mathrm{N}=850)$} & No & 30 & 3.5 \\
\hline & Yes & 820 & 96.5 \\
\hline Artificial abortion history $(\mathrm{N}=820)$ & No & 563 & 68.6 \\
\hline
\end{tabular}




\begin{tabular}{|llll|}
\hline & Yes & 257 & 31.4 \\
\hline Delivery history $(\mathrm{N}=820)$ & No & 9 & 1.1 \\
\hline & Yes & 811 & 98.9 \\
\hline
\end{tabular}

\section{Utilization of RH services}

The utilization of RH services among childbearing women mainly included three aspects in this study: 1) $\mathrm{RH}$ counseling, 2) free birth policy, and 3) RH-related examinations. Of the 850 women who had been sexually active, $53.6 \%$ had contraception counseling and $35.7 \%$ had pregnancy counseling. Among the 820 women who had given birth, the awareness of the free birth policy was the basic public health service policy (47.8\%), the free AIDS, syphilis and hepatitis B testing policy (49.3\%), and the free folic acid supplement policy (78.8\%). Meanwhile, the utilization of RH examination or services was for free AIDS, syphilis and hepatitis B testing (47.5\%), free folic acid supplements $(71.6 \%)$, free preconception care $(27.5 \%)$, free postpartum visits (73.0\%), and free antenatal examinations (90.2\%). Of the 978 women, $36.7 \%$ had cervical cancer screening and $34.0 \%$ had breast cancer screening. (Table 2 ) 
Table 2

Utilization of $\mathrm{RH}$ services ( $\mathrm{N}=978$ )

\begin{tabular}{|c|c|c|c|}
\hline Variables & Categories & Frequencies & Percentages \\
\hline \multicolumn{4}{|l|}{ RH counseling $(n=850)$} \\
\hline \multirow[t]{2}{*}{ Contraception counseling } & No & 394 & 46.4 \\
\hline & Yes & 456 & 53.6 \\
\hline \multirow[t]{2}{*}{ Pregnancy counseling } & No & 547 & 64.3 \\
\hline & Yes & 303 & 35.7 \\
\hline \multicolumn{4}{|l|}{ Free birth policy $(n=820)$} \\
\hline \multirow[t]{2}{*}{ Basic public health service policy } & No & 428 & 52.2 \\
\hline & Yes & 392 & 47.8 \\
\hline \multirow[t]{2}{*}{ Free folic acid supplement } & No & 174 & 21.2 \\
\hline & Yes & 646 & 78.8 \\
\hline \multirow[t]{2}{*}{ Free AIDS, syphilis and hepatitis B testing } & No & 415 & 50.7 \\
\hline & Yes & 405 & 49.3 \\
\hline \multicolumn{4}{|l|}{ RH examination or services } \\
\hline \multirow[t]{2}{*}{ Cervical cancer screening } & No & 619 & 63.3 \\
\hline & Yes & 359 & 36.7 \\
\hline \multirow[t]{2}{*}{ Breast cancer screening } & No & 645 & 66.0 \\
\hline & Yes & 333 & 34.0 \\
\hline \multirow[t]{2}{*}{ Free folic acid supplement $(n=820)$} & No & 233 & 28.4 \\
\hline & Yes & 587 & 71.6 \\
\hline \multirow[t]{2}{*}{ Free AIDS, syphilis and hepatitis B testing $(n=820)$} & No & 431 & 52.5 \\
\hline & Yes & 389 & 47.5 \\
\hline \multirow[t]{2}{*}{ Free antenatal examination $(n=820)$} & No & 80 & 9.8 \\
\hline & Yes & 740 & 90.2 \\
\hline \multirow[t]{2}{*}{ Free preconception care $(n=820)$} & No & 595 & 72.5 \\
\hline & Yes & 225 & 27.5 \\
\hline \multirow[t]{2}{*}{ Free postpartum visit $(\mathrm{n}=820)$} & No & 221 & 27.0 \\
\hline & Yes & 599 & 73.0 \\
\hline
\end{tabular}




\section{Factors associated with the utilization of RH services}

Table 3 presents the results of the logistic regression analysis of the relationship between the utilization of $\mathrm{RH}$ services and the demographic characteristics of the childbearing women after adjusting variables. Artificial abortion history was significantly associated with the use of contraception counseling and pregnancy counseling. Age was significantly associated with the use of antenatal examination. Employment was significantly associated with the use of free folic acid supplements. Spouse education level was significantly associated with the use of postpartum visits. Education level and monthly household income had a significant effect on the use of preconception care, cervical cancer screening, and breast cancer screening. 
Table 3

Social and gestational determinants of $\mathrm{RH}$ services

\begin{tabular}{|c|c|c|c|c|c|}
\hline Social and gestational & Coefficient & OR & $95 \% \mathrm{Cl}$ & & P-Value \\
\hline determinants of $\mathrm{RH}$ services & & & Lower & Upper & \\
\hline \multicolumn{6}{|l|}{ Contraception counseling ${ }^{1}$} \\
\hline Artificial abortion & 0.418 & 1.519 & 1.117 & 2.066 & $0.008^{*}$ \\
\hline \multicolumn{6}{|l|}{ Pregnancy counseling ${ }^{1}$} \\
\hline Artificial abortion & 0.805 & 2.237 & 1.609 & 3.109 & $0.000^{*}$ \\
\hline \multicolumn{6}{|l|}{ Preconception care ${ }^{2}$} \\
\hline Monthly household income & 0.302 & 1.353 & 1.083 & 1.690 & $0.008^{\star}$ \\
\hline Education level & 0.333 & 1.395 & 1.199 & 1.623 & $0.000^{*}$ \\
\hline \multicolumn{6}{|l|}{ Antenatal examination ${ }^{3}$} \\
\hline Age & -0.511 & 0.600 & 0.397 & 0.906 & $0.015^{*}$ \\
\hline
\end{tabular}

Postpartum visit ${ }^{4}$

$\begin{array}{lllllll}\text { Spouse education level } & & 0.283 & 1.328 & 1.100 & 1.603 & 0.003^{*}\end{array}$

Free folic acid supplement ${ }^{5}$
Employment
$-0.565$
$0.568 \quad 0.409$
0.789
$0.001^{*}$

Cervical cancer screening ${ }^{2}$

\begin{tabular}{llllll} 
Monthly household income & 0.418 & 1.518 & 1.253 & 1.840 & $0.000^{*}$ \\
\hline Education level & 0.201 & 1.223 & 1.069 & 1.400 & $0.003^{*}$
\end{tabular}

Breast cancer screening ${ }^{2}$

Monthly household income

0.354

$1.425 \quad 1.176$

1.728

$0.000^{*}$

Education level

0.283

$1.327 \quad 1.156$

1.523

$0.000^{*}$

$\mathrm{Cl}$ Confidence interval, OR odds ratio, ${ }^{*} P \leq 0.05$ indicates statistical significance

1. Adjusting for the region, age, marital status, employment, monthly household income, education level, spouse education level, and sexual behavior.

2. Adjusting for the region, age, marital status, employment, spouse education level, sexual behavior, and artificial abortion history. 
3. Adjusting for the region, marital status, employment, monthly household income, education level, spouse education level, sexual behavior, and artificial abortion history.

4. Adjusting for the region, age, marital status, employment, monthly household income, education level, sexual behavior, and artificial abortion history.

5. Adjusting for the region, age, marital status, monthly household income, education level, spouse education level, sexual behavior, and artificial abortion history.

\section{Demands for RH services}

The findings revealed that the demands for $\mathrm{RH}$ services were highest for prevention of cervical/breast cancer $(58.9 \%)$, child health care $(48.2 \%)$, reproductive tract infection/sexually transmitted disease treatment $(41.1 \%)$, psychological health $(34.0 \%)$, pregnant/prenatal care $(30.7 \%)$, contraception $(19.8 \%)$, climacteric hygiene (11.5\%), and others (2.8\%) (Figure 1$)$.

The most desirable ways to obtain $\mathrm{RH}$ service-related information were the internet (54.8\%), medical staff (54.4\%), WeChat/Micro-blogs (36.1\%), radio and television (29.3\%), friends and family $(26.2 \%)$, books/newspapers/magazines (19.5\%), and brochures (12.3\%) (Figure 2).

\section{Discussion}

The total proportion of females receiving $\mathrm{RH}$ services in rural China was not ideal. Age, monthly household income, employment, spouse education level, and artificial abortion history were associated with the utilization of RH services. The top three $\mathrm{RH}$ services obtained by participants were free antenatal examinations, free postpartum visits, and free folic acid supplements. But all the women failed to reach the national level prescribed by Chinese health authorities. The top three RH services they most wanted to obtain were prevention of cervical/breast cancer, child health care, and reproductive tract infection/sexually transmitted disease treatment. The most commonly used method for participants to obtain information related to $\mathrm{RH}$ services was the internet.

We found that older pregnant women were less likely to have antenatal examinations, which was different from previous studies $[15,16]$. This may be because the proportion of older pregnant women increased under the implementation of the Universal Two-Child Policy. They had multiple pregnancies, and less concerned about maternal and infant health because of poor risk awareness and successful experiences with previous pregnancies $[17,18]$. However, they were usually more likely to experience RH problems like postpartum hemorrhage [19]. In the future, the government should strengthen health education for older pregnant women and increase their attention [20].

The utilization of postpartum visits was below the national level prescribed by Chinese health authorities, and the pregnant women with higher spouse education levels have better access. Postpartum visits play an important role in neonatal feeding and postpartum rehabilitation. The educated husband might be aware of the importance of postpartum in promoting maternal recovery and infant care as noted in a 
recent systematic review [21]. In Chinese traditional culture, parents, as extended family members, are involved in caring for their grandchild. Husbands can greatly influence the decision making of postpartum and infant care [22]. Our results reinforce the importance of targeting families with postpartum visit interventions, not just individual mothers.

We observed that the utilization of free folic acid supplements is far below the national level, and the unemployed women had better access. The State Council of the People's Republic of China proposed in its National Nutrition Plan (2017-2030) that the folic acid deficiency rate of pregnant women should be kept below 5\% [13].

One study showed that $52 \%$ of rural maternal and child health workers did not know the appropriate dose of folic acid per day [23]. As noted in a recent systematic review, most women think they did not need folic acid if they were having a healthy pregnancy, and think it is inconvenient to get folic acid from the community [24]. Besides, women with jobs were too busy to have time for follow-up or get folic acid from the community $[23,25]$. Therefore, it is necessary to popularize the importance of folic acid supplement to pregnant women and rural maternal and child health workers. Also, the establishment of a more flexible method of folic acid delivery may facilitate folic acid supplements. For example, all pregnant women without contraindications could get a free folic acid supplement at a nearby pharmacy [26].

We observed that the utilization of free preconception care, cervical cancer screening, and breast cancer screening were not ideal. The above three examinations are of great significance in eugenics and early diagnosis of cancer. Our research showed that women with low education levels and monthly household incomes had worse utilization. This means they will bear a greater burden and risk of disease, and more vulnerable to poverty $[27,28]$. Also, it is difficult for them to take positive measures after the occurrence of the disease [29]. Therefore, how to take effective measures to improve the RH of the low-income and loweducation population is still an urgent problem.

Remarkably, women with artificial abortion history were more likely to use contraceptive counseling and pregnancy counseling services in our research. In China, the artificial abortion rate is $52.9 \%$, yet artificial abortions can cause uterine adhesions, infertility, and other reproductive health problems [12, 30]. Unsafe artificial abortion can cause uterine perforation and uterine rupture [31]. Contraceptives play an important role in preventing unnecessary artificial abortion, but there are problems of stigmatization and improper management in the process of providing contraceptives [32,33].Further studies need to research how to build a stronger system and strengthen management to improve the quality of services.

The $\mathrm{RH}$ service participants in the study most wanted to receive is the prevention of cervical/breast cancer. This may be because cervical cancer and breast cancer are the most common malignant tumors in women [34]. The incidence rate of breast cancer ranks first in female malignant tumors. There are about 2.1 million new cases and 627,000 deaths worldwide in 2018 [35]. As for cervical cancer, there are about 570,000 new cases worldwide, while the number of cervical cancer patients in China reached 45,200 in $2018[12,35]$. The whole process HPV vaccine has not yet covered all regions, which is 
voluntary and expensive in China [36]. Unhealthy lifestyle and high-intensity work also increase the risk of breast cancer [37]. Therefore, the popularization of cancer prevention knowledge is particularly important.

Our study also found that women were most likely to access RH service-related information through the internet. At present, a mobile health program has been widely recognized as an effective method for improving health services due to the ease in obtaining information without limitations of time and space [38-40]. Moreover, other ways of obtaining RH service-related information-lectures, brochures, magazines, video and television-should be given more attention to satisfy the different groups, especially in underdeveloped areas lacking the internet.

\section{Strengths And Limitations}

Our study had the following advantages. This was the first study in central rural China to investigate the utilization of and demand for RH Services among childbearing women after the implementation of the Universal Two-Child Policy. Our study was based on a large sample of childbearing women in Mainland China. We selected four regions to control sampling errors, and all the participants were recruited from communities, not hospitals or obstetric units. This approach may increase the representativeness of the sample and make the findings more generalizable.

Some methodological limitations need to be recognized. First, since the results were based on selfreported data, memory bias and concealment of information were possible. Second, owing to the crosssectional design, no causation could be inferred. Thus, a well-designed longitudinal study is warranted. Third, our study only describes the current situation and needs, and more intervention studies are needed to promote the utilization of reproductive health services. Finally, $\mathrm{RH}$ is a shared problem of couples. We need more research to determine whether the husbands' attitudes may influence their wives' decisions about whether to access RH services.

\section{Conclusion}

Although the Chinese government has proposed a plan to promote equal access to $\mathrm{RH}$ services in rural areas, it is necessary to further improve the accessibility and availability of RH services to ameliorate the utilization of these services. The internet may be one of the best and most effective methods for enhancing $\mathrm{RH}$ knowledge and improving the use of RH services. Future efforts should target high-risk populations of women who are older, low-income, low-education level, or employed by providing them with $\mathrm{RH}$-related information and cultivating positive attitudes toward $\mathrm{RH}$ services.

\section{Abbreviations}

RH: Reproductive Health; UN: United Nations; SDG: Sustainable Development Goals; HPV: Human Papillomavirus; NCSPRA: National Cancer Screening Program in Rural Areas. 


\section{Declarations}

\section{Ethics approval and consent to participate}

The study was approved by the Ethical Committee of Xiang Ya Nursing School, Central South University. Written consent was obtained from all respondents before the interview.

\section{Consent of publication}

Not applicable.

\section{Availability of data and materials}

Data will be available upon request from the corresponding author.

\section{Competing interests}

The authors declare that they have no conflicts of interest.

\section{Funding}

The project was supported by the Hunan Women's Research Association, China (Grant No. 20YB03). The funding body was not responsible for study design, data collection, analysis, or interpretation.

\section{Authors' contributions}

JY conceived, designed the study and drafted the manuscript. YTM, CX, SQ, LF and MN help data collection and entry. YL revised the manuscript, providing intellectual content. All authors commented on and approved the final manuscript.

\section{Acknowledgments}

We thank those who participated in this study and acknowledge the outstanding support provided by Hunan province and the local Women's Federation, Office of the Committee for Women and Children's Workers and Health Administration in Hunan province, China. We also thank Scribendi [www.scribendi.cn] for English language editing.

\section{References}


1. Population and development. Programme of action adopted at the International Conference on Population and Development, Cairo, 5e13 September 1994. New York: United Nations, Dept. for Economic and Social Information and Policy Analysis; 1995.

2. LV X, Yan B. Analysis of problems and promotion strategies of female reproductive health. Scientific health, 2019, (7): 234204.

3. Glasier A, Gülmezoglu AM, Schmid GP, Moreno CG, Van Look PF. Sexual and reproductive health 1: Sexual and reproductive health: A matter of life and death. Lancet. 2019;368:9547: 1595-607. doi:10.1016/S0140-6736(06)69478-6.

4. Sustainable Development Goals. The United Nations. https://. Accessed August 30, 2020.

5. Sepulveda J, Murray C. The state of global health in 2014. Science. 2014;345(6202):1275-8. doi:10.1126/science.1257099.

6. WHO/UNICEF estimates of human. papillomavirus (HPV) vaccine coverage estimates. July 2019 revision. https:/// Accessed August 30, 2020.

7. Sun LY, Xing QH, He L. Retrospect and prospect of the genetic research on birth defects in China. Yi Chuan. 2018;40(10):800-13. doi:10.16288/j.yczz.18-181.

8. Report on the development of maternal and child health in China. (2019). National Health Commission of the People's Republic of China. Department of maternal and child health, 2019. http://www. nhc.gov.cn/ Accessed August 30, 2020.

9. World Demographics. 2020 (Population, Age, Sex, Trends). Worldometer. https://www.worldometers.info/demographics/world-demographics/ Accessed October 10, 2020.

10. China Statistical Yearbook. 2019. National Bureau of Statistics of China. http:// Accessed August 30, 2020.

11. Zeng Y, Hesketh T. The effects of China's universal two-child policy. Lancet. 2016;388(10054):19308. doi:10.1016/S0140-6736(16)31405-2.

12. National Health Commission. China Health Statistics yearbook [M]. Volume 2019. Beijing: Peking Union Medical College Press; 2020.

13. Chinese Nutrition Society. National Nutrition Program. (2017-2030). Acta Nutrimenta Sinica. 2017, 39(4): 315-320, 312.doi:10.3969/j.issn.0512-7955.2017.04.002.

14. Wang H, Chen B, Xu Y, Miao Q, Wu Z, Ju Q, Huang Y. View changes and educational demands on sexual/reproductive health of students at Shanghai Jiaotong University. Int J Clin Exp Med. 2015;8(9):16414-23.

15. Zhou Y, Wang T, Fu J, Chen M, Meng Y, Luo Y. Access to reproductive health services among the female floating population of childbearing age: a cross-sectional study in Changsha, China. BMC Health Serv Res. 2019 Aug 1;19(1):540. doi: 10.1186/s12913-019-4334-4.

16. Zhao ZL, Liu Z, Liu J, Xv XR, Wang HJ, Luo SS. Study on compliance of prenatal care in Tongzhou District of Beijing. Chinese Journal of reproductive health. 2019;30(5):401-6. doi:10.3969/j.issn.1671-878X.2019.05.001. 
17. Tian C, Peng H, Lee Soowon, Xu Y, Li YM, Zhu Q, et al. Analysis of maternal and child health care during pregnancy from 2012 to 2018. Chinese Journal of Woman Child Health Research. 2020;31(5):546-52. doi:10.3969/j.issn.1673-5293.2020.05.001.

18. Wu BH, Jin CY, Wang HY, Li N, Li ZW. Analysis on the changes of elderly maternal and parity in a tertiary hospital in northern China since the "Universal Two-Child" policy. Chinese Journal of Reproductive Health. 2018;29(3):201-4. doi:10.3969/j.issn.1671-878X.2018.03.001.

19. Kramer MS, Berg C, Abenhaim H, Dahhou M, Rouleau J, Mehrabadi A, Joseph KS. Incidence, risk factors, and temporal trends in severe postpartum hemorrhage. Am J Obstet Gynecol. 2013 Nov;209(5):449.e1-7. doi:10.1016/j.ajog.2013.07.007.

20. Pan X, Zhang J, Zhang XW. Application research progress of centralized group pregnancy health care mode abroad. Chinese Journal of Nursing. 2016;51(8):988-91. doi:10.3761/j.issn.02541769.2016.08.020.

21. Adams YJ, Smith BA. Integrative Review of Factors That Affect the Use of Postpartum Care Services in Developing Countries. J Obstet Gynecol Neonatal Nurs. 2018;47(3):371-84. doi:10.1016/j.jogn.2018.02.006.

22. Xiao X, Ngai FW, Zhu SN, Loke AY. The experiences of early postpartum Shenzhen mothers and their need for home visit services: a qualitative exploratory study. BMC Pregnancy Childbirth. 2019 Dec 31;20(1):5. doi:10.1186/s12884-019-2686-8.

23. Xie $\mathrm{CH}$, Liang HY. Analysis on the current situation of free folic acid distribution in Xinhui Area in three years. Journal of Baotou Medical College. 2016;32(4):12-3.

24. Siekmans K, Roche M, Kung'u JK, Desrochers RE, De-Regil LM. Barriers and enablers for iron folic acid (IFA) supplementation in pregnant women. Matern Child Nutr. 2018 Dec;14(Suppl 5):e12532. doi:10.1111/mcn.12532. Suppl 5 ) .

25. Xiong J, Chen Z, Shen XZ, Zheng J, Peng MD, Chen Y, et al. Application of new health path management model in supplement of folic acid to prevent neural tube defects project. Maternal Child Health Care of China. 2017;32(3):435-8. doi:10.7620/zgfybj.j.issn.1001-4411.2017.03.02.

26. Hu XL, Li MD. Practice and active exploration to create a precise service brand of folic acid supplement and pre pregnancy eugenic health examination project. Chinese Journal of Family Planning. 2017;25(6):417-9. doi:10.3969/j.issn.1004-8189.2017.06.017.

27. Liu ZY, Li J, Hong Y, Yao L. Reproductive health service utilization and social determinants among married female rural-to-urban migrants in two metropolises, China. J Huazhong Univ Sci Technolog Med Sci. 2016;36(6):904-9. doi:10.1007/s11596-016-1682-8.

28. Abekah-Nkrumah G. Spatial variation in the use of reproductive health services over time: a decomposition analysis. BMC Pregnancy Childbirth. 2018;18(1):63. doi:10.1186/s12884-018-1695-3.

29. Chen M, Luo Y, Fu J, Xu C, Qin S, Meng Y. Reproductive health status and related knowledge among women aged 20-39 years in rural China: a cross-sectional study. Reprod Health. 2020;17(1):90. doi:10.1186/s12978-020-00939-2. 
30. Yang XX. Risk factors of secondary infertility in women of childbearing age after induced abortion. Maternal Child Health Care of China. 2020;35(15):2856-8. doi:10.19829/j.zgfybj.issn.10014411.2020.15.039.

31. Calonge BN, Gayle HD. The Safety and Quality of Abortion Services in the United States: What Does the Evidence Indicate? Ann Intern Med. 2018;168(12):878-80. doi:10.7326/M18-0662.

32. Pang XX. Discussion on the distribution and management of family planning contraceptives. Chinese Baby, 2018, (6): 234.doi:10.3969/j.issn.1671-2242.2018.06.225.

33. Xv LJ. Reform of management and supply system of free contraceptives at the grassroots level. Chinese Journal of Urban Rural Enterprise Hygiene. 2018;33(11):178-80. doi:10.16286/j.10035052.2018.11.078.

34. Wilm J, Schüler-Toprak S, Ortmann O. Screening for cervical and breast cancer. Pathologe. 2016;37(5):477-89. doi:10.1007/s00292-016-0228-y.

35. Wild CP, Weiderpass E, Stewart BW. World Cancer Report: Cancer research for cancer prevention. Lyon: International Agency for Research on Cancer; 2020.

36. Zhang SQ, Wang K, Zhang YL. Application status of HPV vaccine in China. Chinese Journal of Practical Gynecology obstetrics. 2019;35(10):1090-5. doi:10.19538/j.fk2019100105.

37. Sun YS, Zhao Z, Yang ZN, Xu F, Lu HJ, Zhu ZY. etc. Risk Factors and Preventions of Breast Cancer. Int J Biol Sci. 2017 Nov 1;13(11):1387-1397. doi:10.7150/ijbs.21635.

38. Sim I. Mobile devices and health. N Engl J Med. 2019;381(10):956-68. doi:10.1056/NEJMra1806949.

39. Arbour MW, Stec MA. Mobile Applications for Women's Health and Midwifery Care: A Pocket Reference for the 21st Century. J Midwifery Womens Health. 2018;63(3):330-4. doi:10.1111/jmwh.12755.

40. Teitelman AM. Using Mobile Technologies to Improve Women's Health. J Obstet Gynecol Neonatal Nurs. 2018;47(6):830-2. doi:10.1016/j.jogn.2018.09.004.

\section{Figures}

\section{The percentage of participants who most want to receive each kind of RH services}

$\begin{array}{r}\text { Others } \\ \text { Climacteric hygiene } \\ \text { Contraception } \\ \text { Pregnant/Prenatal care } \\ \text { Psychological health }\end{array}$
Reproductive tract infection/Sexually transmitted diseases treatment
Child health care


Figure 1

The most desirable RH services by percentage of participants

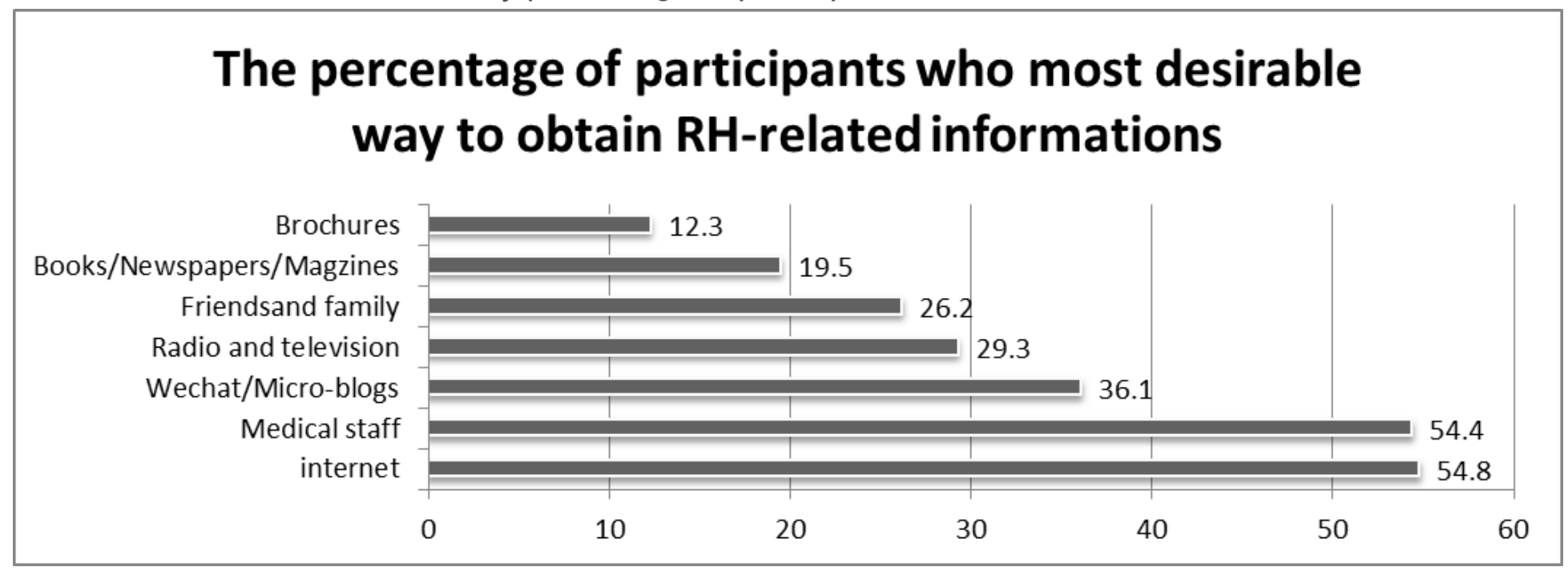

Figure 2

The most desirable ways of obtaining $\mathrm{RH}$-related information by percentage of participants

\section{Supplementary Files}

This is a list of supplementary files associated with this preprint. Click to download.

- completedSTROBEcrosssectionalchecklist1.docx 